\title{
THE ACCUMULATION OF REPRODUCTIVE INCOMPATIBILITIES IN AFRICAN CICHLID FISH
}

\author{
Rike B. Stelkens, ${ }^{1,2,3,4}$ Kyle A. Young, ${ }^{5}$ and Ole Seehausen ${ }^{3,4}$ \\ ${ }^{1}$ Department of Ecology and Evolution, University of Lausanne, Biophore, CH-1015 Lausanne, Switzerland \\ ${ }^{2}$ E-mail: Rike.Stelkens@unil.ch \\ ${ }^{3}$ Division of Aquatic Ecology, Institute of Ecology and Evolution, University of Bern, Baltzerstr. 6, CH-3012 Bern, \\ Switzerland \\ ${ }^{4}$ Department of Fish Ecology and Evolution, Centre of Ecology, Evolution and Biogeochemistry (CEEB), Eawag Swiss \\ Federal Institute of Aquatic Science and Technology, Seestrasse 79, CH-6047 Kastanienbaum, Switzerland \\ ${ }^{5}$ Environment Agency, Lutra House, Walton Summit, Preston, United Kingdom PR5 8BX
}

Received March 23, 2009

Accepted September 2, 2009

\begin{abstract}
The rate at which different components of reproductive isolation accumulate with divergence time between species has only been studied in a limited, but growing, number of species. We measured premating isolation and hybrid inviability at four different ontogenetic stages from zygotes to adults in interspecific hybrids of 26 pairs of African cichlid species, spanning the entire East African haplochromine radiation. We then used multiple relaxed molecular clock calibrations to translate genetic distances into absolute ages to compare evolutionary rates of different components of reproductive isolation. We find that premating isolation accumulates fast initially but then changes little with increasing genetic distance between species. In contrast, postmating isolation between closely related species is negligible but then accumulates rapidly, resulting in complete hybrid inviability after 4.4/8.5/18.4 million years (my). Thus, the rate at which complete intrinsic incompatibilities arise in this system is orders of magnitude lower than rates of speciation within individual lake radiations. Together these results suggest divergent ecological adaptations may prevent populations from interbreeding and help maintain cichlid species diversity, which may be vulnerable to environmental degradation. By quantifying the capacity to produce viable hybrids between allopatric, distantly related lineages our results also provide an upper divergence time limit for the "hybrid swarm origin" model of adaptive radiation.
\end{abstract}

KEY WORDS: Adaptive radiation, cichlid fish, divergence time, genetic distance, hybrid (in)viability, relaxed molecular clock, reproductive isolation, speciation.

Quantifying the rates at which different components of reproductive isolation accumulate through time is a fundamental goal of evolutionary research because it provides insight into speciation mechanisms (Otte and Endler 1989; Howard and Berlocher 1998; Turelli et al. 2001; Coyne and Orr 2004). These components can be classified into pre- and postmating isolation (Coyne and Orr 2004). Premating reproductive isolation results from interactions between males and females that affect the likelihood of heterospecific matings (e.g., mating preferences, courtship location, timing, and behavior). Intrinsic postmating reproductive isolation results principally from the negative effects of Dobzhansky-Muller genetic incompatibilities on stage-variable survival rates to adulthood, e.g., fertilization success and hatching rates (Dobzhansky 1936; Muller 1942; Lynch 1991; Edmands 1999; Gharrett et al. 1999; Turelli and Orr 2000). Reproductive isolation can also result from extrinsic ecological or sexual selection if hybrids are ecologically or reproductively less successful than individuals of the parent species (Hatfield and Schluter 1999; Vamosi and Schluter 1999; Naisbit et al. 2001; Fuller 2008; van der Sluijs et al. 2008b). This illustrates a difficulty with the distinction into 
pre- and postmating isolation because implicitly, this categorization only refers to mating of the parents. However, hybrids might also fail to find mates that may be considered a premating barrier (Noor 1997), or they are sterile that usually falls under postmating isolation, yet both forms of isolating mechanisms are traditionally listed under the postmating rubric.

The geographical mode of speciation is predicted to affect the relative rate at which pre- and postmating incompatibilities accumulate (Coyne and Orr 1989, 1997). Because reinforcement can occur only in sympatry, premating incompatibilities are expected to accumulate faster than intrinsic postmating incompatibilities in a sympatric setting. At the same time some have argued that in allopatry, the two classes of incompatibilities are expected to accumulate at similar rates because divergent selection and genetic drift should affect traits contributing to each form of incompatibility similarly (Dobzhansky 1951; Butlin 1989; Coyne and Orr 1989, 1997; Rundle and Schluter 1998; Jiggins et al. 2001; Nosil et al. 2003; Coyne and Orr 2004; Servedio 2004; Bridle et al. 2006). Theory also suggests that premating incompatibility may accumulate rapidly in allopatry when species are characterized by sexual dimorphism and strong sexual selection (Fisher 1930; Lande 1981; West-Eberhard 1983). For example, Mendelson (2003) found that premating incompatibility accumulated faster than hatching incompatibility among allopatric species pairs of sexually dimorphic darter fish (Etheostoma).

Among others, Coyne and Orr (1989) were the first to apply the approach of comparing the degree of premating or postmating incompatibility to interspecific genetic distance, which when calibrated to absolute time using molecular clocks, yields the well-known "speciation clock" (Parker et al. 1985a,b; Edmands 2002; Bolnick and Near 2005; Bolnick et al. 2006). Despite important progress, the full potential of the approach has remained unrealized for two principal reasons. First, divergence times are typically estimated from molecular clocks that lack calibration to the fossil/geologic record and assume constant substitution rates through time and across lineages (Coyne and Orr 1989, 1997; Knowlton et al. 1993; Foltz 1997; Sasa et al. 1998; Presgraves 2002; Tubaro and Lijtmaer 2002; Lijtmaer et al. 2003; Mendelson 2003; Moyle et al. 2004; Malone and Fontenot 2008; for exceptions see Price and Bouvier 2002; Fitzpatrick 2004; Bolnick and Near 2005). This uncertainty makes it difficult to interpret or compare the wide range (1.5-29 my) of published estimates for the waiting time to complete incompatibility (Coyne and Orr 1989; Knowlton et al. 1993; Coyne and Orr 1997; Turelli and Begun 1997; Sasa et al. 1998; Presgraves 2002; Price and Bouvier 2002; Lijtmaer et al. 2003; Bolnick and Near 2005). Second, most studies have quantified the relationship between estimated divergence time and a measure of either premating isolation or postmating incompatibility. Most of the studies that have compared the two rates have done so for only a single measure of postmating in- compatibility (Coyne and Orr 1989, 1997; Gleason and Ritchie 1998; Mendelson 2003; Moyle et al. 2004). We know of only two studies in animals (Sasa et al. 1998; Malone and Fontenot 2008), and of two in plants (Scopece et al. 2007; Lowry et al. 2008), that have compared a measure of premating isolation with measures of postmating incompatibility at multiple life stages. It may be inappropriate to draw conclusions about the rate at which postmating incompatibility accumulates based on fertilization or hatching success if genetic incompatibilities are expressed during later ontogenetic stages.

Here we address both these limitations using the adaptive radiation of East African haplochromine cichlid fish. We used 16 different species, which —although being only a subset of the whole East African haplochromine radiation-span the phylogenetic depth and age of the entire radiation. For 26 (mostly allopatric) species pairs, we estimated the strength of premating isolation and quantified hybrid viability from fertilization through to adulthood for heterospecific and homospecific (parental) crosses. We then quantify the relationship between incompatibility and time since isolation using three different molecular clocks: one linear clock calibrated to the biogeography of Lake Malawi (Sturmbauer et al. 2001), and two nonlinear clocks, one calibrated to the fossil record plus recent biogeographical events, the other to the break up of Gondwanaland and recent biogeographical events (Genner et al. 2007).

Studying the rate at which reproductive compatibility declines in African cichlid radiations is interesting for several reasons. First, cichlids are typically sexually dimorphic with male breeding color under sexual selection through female choice (Seehausen 1997; Knight and Turner 2004; Maan et al. 2004; Pauers et al. 2004; Stelkens et al. 2008; van der Sluijs et al. 2008a). For such systems, theory predicts that premating compatibility may be lost faster than intrinsic postmating compatibility (Fisher 1930; Lande 1981; West-Eberhard 1983). Second, evidence suggests that some adaptive radiations of cichlids may have been initiated through hybridization between distantly related lineages (Seehausen 2004). For example, the radiations of Lake Victoria (Seehausen et al. 2003) and paleo-Lake Makgadikgadi (Joyce et al. 2005) appear to be derived from multiple distantly related lineages. Quantifying the rates at which different components of reproductive compatibility are lost between isolated cichlid lineages is important for understanding the role of hybridization in adaptive radiation.

\section{Methods \\ GENETIC DISTANCE AND DIVERGENCE TIME ESTIMATES}

Genetic distances between species pairs were calculated as uncorrected p-distances using all available D-loop sequences in 
NCBI GenBank (http://ncbi.nlm.nih.gov/Genbank/; Table S1). Sequences were manually aligned following pairwise algorithm alignment in ClustalW (Thompson et al. 1997). Genetic distances were calculated in MEGA 4 (Kumar et al. 2004). For species without sequences on GenBank, we used the sequences of closely related species (Table S1). This is justified because all missing and replacement species were members of clades with incomplete mitochondrial DNA lineage sorting (the radiation of Lake Victoria and species within subclades of Lake Malawi Mbuna). Sequences were available for all species pairs with complete lineage sorting. When multiple sequences were available, we used the average p-distance (Mendelson 2003; Chapman and Burke 2007). All interspecific distances were corrected for intraspecific variation among haplotypes by subtracting average withinspecies distances (mean of the intraspecific average distances of both species per cross) from mean between-species distances (Nei 1987; Mendelson 2003).

Divergence times were calculated using three molecular clocks. The first two were relaxed clocks calibrated using the cichlid fossil record and the fragmentation of Gondwanaland (Genner et al. 2007). We used the power functions of Genner et al. (fig. $5 \mathrm{~d}$ in their paper), which show divergence in the D-loop region of mitochondria is rapid for one million years then declines until reaching a stable baseline substitution rate at two million years. Similar nonlinear patterns have been found in birds and primates (Ho and Larson 2006; Ho 2007). The third clock was internally calibrated using the age of Lake Malawi (Sturmbauer et al. 2001).

\section{BREEDING PROTOCOL}

The specific species pairings used in this study were chosen from the stock of different species maintained in our holding facilities at EAWAG, Switzerland, such as to maximize the variance in genetic relatedness. All fish used in the experiment were either derived from large laboratory populations or collected in the wild (Sargochromis, Pseudocrenilabrus). Hybrid families were created between October 2005 and August 2007 in aquaria (100 × $40 \times 40 \mathrm{~cm})$ stocked with 5-20 females and a single male. A shelter of three stones served as the male territory. Fish were fed daily with dry food and twice a week with a blend of shrimp, peas and Spirulina powder. Light regime was 12L:12D and water temperature was $24-26^{\circ} \mathrm{C}$. All study species are maternal mouthbrooders. Tanks were checked daily for brooding females, which were left in the aquarium for four days to avoid premature release of the eggs. Eggs were then collected by holding the female vertically in the water and gently opening her mouth. Males and females that had spawned were replaced with new individuals to avoid pseudoreplication and to keep the number of fish per tank constant.

\section{MEASURING PREMATING ISOLATION}

The experimental unit of observation for measuring premating isolation was the aquarium. We used the proportion of females that did not spawn (1 - number of spawned females/total number of females, Table S2) to estimate the strength of premating reproductive isolation, with values near " 1 " indicating nearly complete premating isolation. The denominator here contains the number of females present in the tank at the time of spawning (which remained constant because spawned females were replaced by unspawned females), not the total number of different individual females that were employed over the course of the entire experiment (the number of females per tank can be found in Table S2). Hence, the number of times a replacement took place had no effect on the calculation of premating isolation. If crosses were made in more than one tank, we used the average across tanks. Breeding experiments were terminated once enough hybrid families were obtained or when it became clear that no more spawnings would occur. Hence, trials lasted for different lengths of time (from 24 to 593 days, Table S2). To test if the duration of trials affected our estimate of premating isolation, we regressed the isolation index on trial duration. We also regressed trial duration on genetic distance.

We know from experience that even in homospecific crosses rarely do all females in a tank breed, regardless how much time they are given. Although it would have been ideal, time and space constraints did not allow us to collect premating data for all species used in this experiment. Thus, in absence of data from homospecific control tanks, we estimated the proportion of females that did not spawn with conspecific males from data on three different species of Pseudocrenilabrus from Lake Mweru, Zambia/DCR (Stelkens and Seehausen 2009), and two species of Pundamilia from Lake Victoria (Stelkens et al. 2008; C. J. Allender and O. Seehausen, unpubl. data). In these experiments, females were tested for assortative mating between conspecific males and males of closely related species. We used the same calculation as above, but subtracted the number of females that spawned with the heterospecific male (1 - number of spawned females/(total number of females - females spawning with a heterospecific male)). We use the mean isolation index from these five crosses as a homospecific comparison (i.e., premating isolation at $\sim$ zero genetic distance) to the levels of isolation observed in our interspecific mating trials.

The proportion of nonbreeding females was regressed on each of the three estimates of divergence time. The homospecific control datapoint was not included in the regression analyses but is shown in the figures for comparison and is used to facilitate comparisons with indices of hybrid inviability. We used stepwise general linear models in S-PLUS 7.0 (1999) with linear and quadratic terms, using AIC to select the best model. 


\section{MEASURING HYBRID INVIABILITY}

We measured hybrid inviability for four life-history stages: (1) fertilization, (2) hatching, (3) survival rate at 14 days, and (4) survival at day 180 , which in cichlids corresponds to early adulthood and sexual maturity.

Fertilization failure per clutch was calculated as $1-$ (number of fertilized eggs/total number of eggs) five days after mating (fertilized eggs are easily distinguished by color and texture). Fertilized eggs were transferred to identical egg tumblers (description available from the corresponding author). Hatching failure per clutch was calculated as 1 - (number of hatched/number of fertilized eggs). Mortality after 14 days was calculated as 1 (number of survivors on day 14/number of hatchlings). Dead eggs and fry were removed from the tumblers daily to avoid mold infection. On day 15 , all fry were moved to aquaria $(20 \times 40 \times$ $20 \mathrm{~cm}$ ), maintained at the same light and temperature conditions as above. On day 30 , the fish were transferred into larger aquaria $(50 \times 40 \times 30 \mathrm{~cm})$ at a maximum density of 20 individuals per aquarium. Fish were fed daily at a constant per-fish-rate. For each clutch, we calculated 180-day mortality as $1-$ (number of survivors on day 180/number of individuals on day 30). Finally, we calculated the total (cumulative) hybrid inviability as $1-$ (number of survivors on day 180/total number of eggs laid). All measures of hybrid inviability were regressed against divergence time using the same stepwise procedure as above (except for cumulative inviability where a logarithmic model provided the best fit).

\section{CALCULATING INCOMPATIBILITY}

To control for homospecific levels of fertilization failure and mortality, we raised three clutches of each parental species using the identical procedure and measured the same four components of inviability. We calculated incompatibility for each of the four measures and cumulative inviability using equation (1) (Bolnick and Near 2005). Values of the two homospecific cross types were averaged. Because most cross types were replicated (for sample sizes per cross type see Table 1), we used the average of multiple clutches for each cross type (reciprocal crosses pooled)

$$
\text { incompatibility }=1-\frac{\% \text { success in heterospecific crosses }}{\% \text { success in homospecific crosses }} \text {. }
$$

Incompatibilities approaching 1 indicate nearly complete failure at a given life-history stage, whereas those close to zero indicate hybrids have similar fertilization/hatching/survival rates as homospecifics. The incompatibility data were analyzed as above.

\section{CONTROLLING FOR THE NONINDEPENDENCE OF PAIRWISE RELATIONSHIPS}

To estimate the phylogenetic relationship of the 16 species, we calculated p-distances using mitochondrial D-loop sequences
(903 bp) and performed neighbor joining analysis with 1000 bootstrap pseudoreplicates in MEGA (Kumar et al. 2004) (Fig. 1). We then calculated independent contrasts for all test variables across each node in the phylogeny (Felsenstein 1985). Following Coyne and Orr $(1989,1997)$, we calculated means for each node by averaging the values for all species pairs that span the node without controlling for branch length variation.

Contrasts were calculated for (1) the strength of premating isolation and the different measures of hybrid inviability; (2) the incompatibility of hybrid crosses after controlling for the incompatibility observed in homospecific crosses. The first analysis was used to compare the rates at which pre- versus postmating isolation accumulate. The independent contrast data were analyzed following the same stepwise procedure as applied to the raw data. Because sample sizes decreased quickly from raw data to contrast data, we present the results from both datasets side by side for a better visual comparison (Fig. 2 and Fig. A1).

\section{Results}

We obtained 26 cross types from parents of 16 haplochromine cichlid species with divergence times ranging from several thousand years to 6.6/10/22 my (from here forward divergence time estimates are given in the following order: the internal calibration/fossil calibration/Gondwana calibration). Table 1 reports crosses with genetic distances, divergence times, and sample sizes for the different pre- and postmating measures. We received data on reciprocal crosses from only 11 of the 26 cross types, because for some species pairings not enough individuals were available to set up experiments in both sex directions.

\section{PREMATING ISOLATION}

The proportion of females that spawned did not depend on trial duration $\left(R^{2}=0.02 ; F_{1,57}=1.11, P=0.3\right)$, and trial duration was not related to the genetic distance between parents $\left(R^{2}=0.02\right.$; $F_{1,57}=0.86, P=0.29$, Table S2).

The proportion of nonbreeding females increased significantly with divergence time and was best explained by a linear model for all three clock estimates (Fig. 2). The average proportion of nonbreeding females in homospecific crosses of three Pseudocrenilabrus and two Pundamilia species was $0.44 \pm 0.15$. To obtain an intercept for the relationship between premating isolation and divergence time, we subtracted the homospecific value (0.44) from all heterospecific values and reran the analysis (all results in Table 2A). Despite the smaller sample size, the phylogenetically independent contrasts yielded nearly identical results (Fig. 2). The proportion of nonbreeding females increased significantly with node age based an all three molecular clocks. Again, the homospecific value was subtracted from all datapoints to obtain an estimate of the intercept (Table 2B). Based on the 


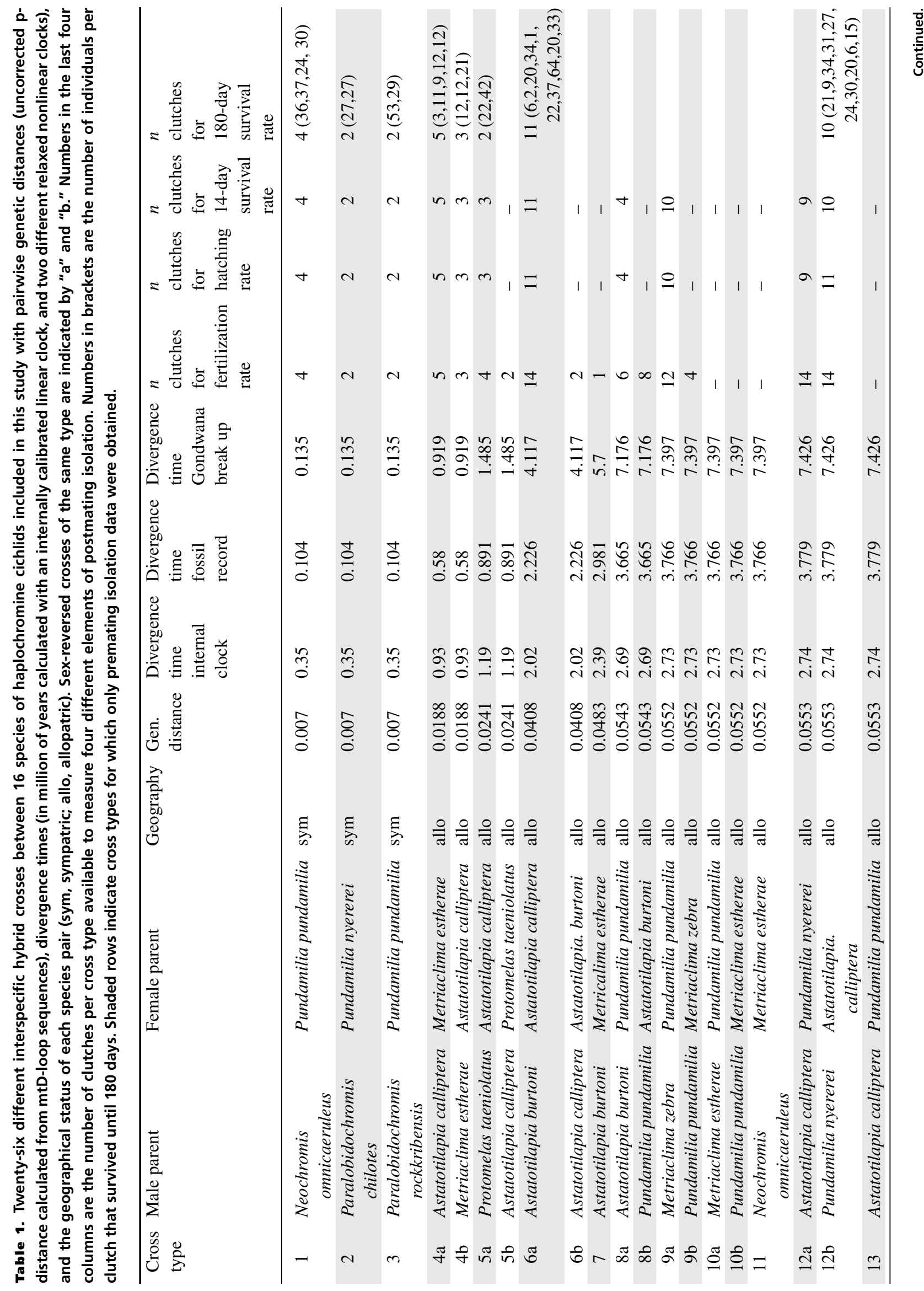




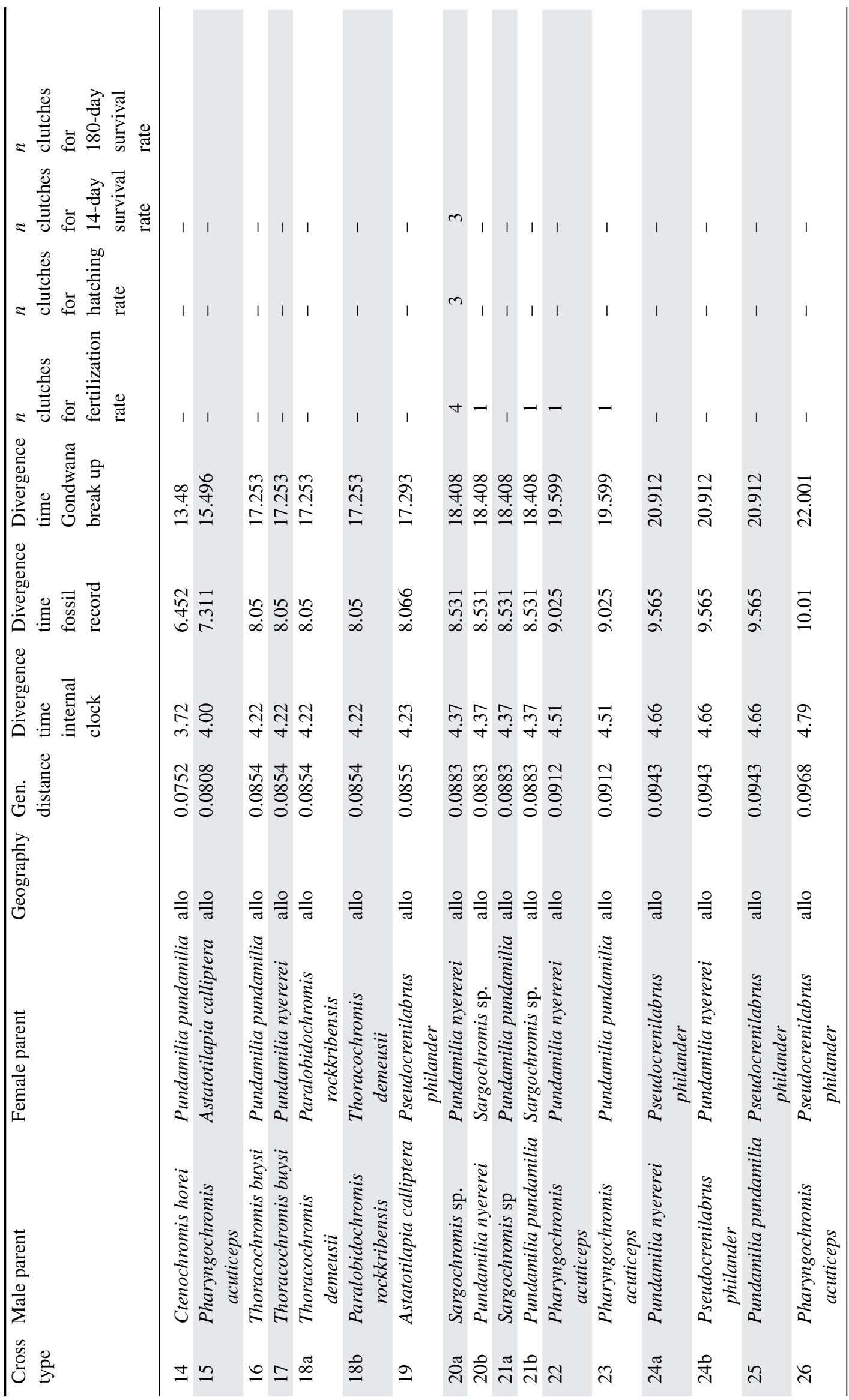




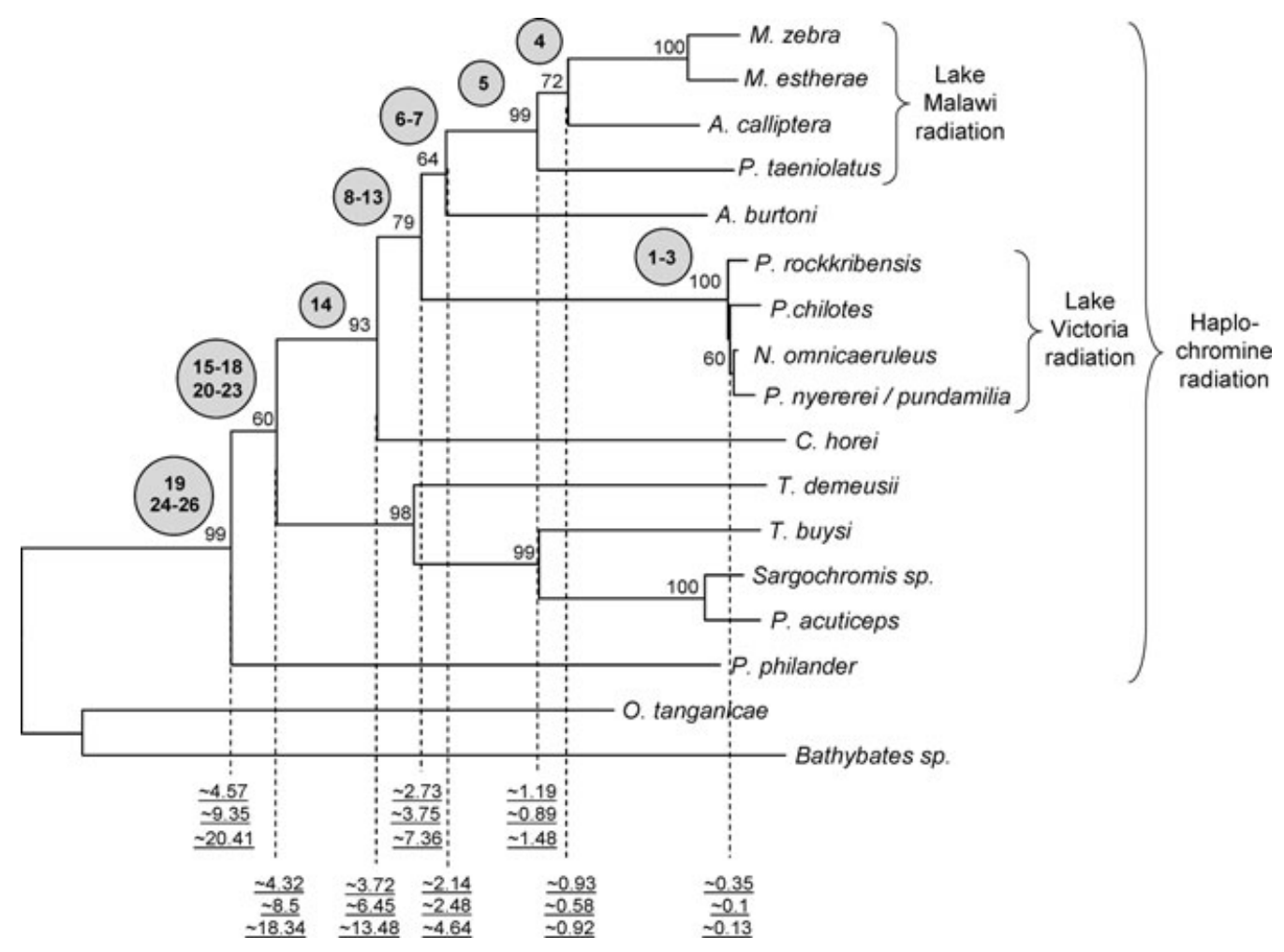

Figure 1. Neighbor-joining estimate of the phylogeny of the entire East African radiation of haplochromine cichlid fish, featuring the 16 species used in this study to make interspecific crosses. Only values $>\mathbf{5 0} \%$ are shown for 1000 bootstrap pseudoreplicates. Numbers in circles correspond to the hybrid crosses described in Table 1 and indicate the eight nodes in the phylogeny for which independent contrasts in reproductive isolation and divergence time were calculated. Cross 19 is not in consecutive order because in Table 1 it was assigned a slightly smaller p-distance than the other crosses spanning that node. This was due to the high intraspecific genetic distances found in both its parental species, which was subtracted from the interspecific distance. The clades representing the endemic radiations of Lake Malawi ( 500 spp), Lake Victoria ( $500 \mathrm{spp}$ ), and the entire East African radiation are indicated. Divergence times in millions of years are shown underneath the tree. Upper values indicate node ages calculated from a linear, internally calibrated clock using only recent biogeographical events, middle values show node age estimates from a nonlinear clock based on the fossil record plus recent biogeographical events, lower values show node ages from a nonlinear clock based on the break up of Gondwanaland plus recent biogeographical events. Values represent average divergence time estimates of all crosses spanning that node. The closely related sister species $P$. nyererei and $P$. pundamilia were treated as one taxon in this phylogeny.

regression model (using contrast data) premating isolation reached $50 \%$ after ca. 1.4/1.0/1.7 my and complete isolation well after $>4.8 / 10 / 22$ my (Fig. 2). The intercepts of the regressions were consistently greater than, but not significantly different from the homospecific control value (using raw data: $t=0.54 / 0.45 / 0.43, P=0.59 / 0.66 / 0.67$; using contrast data: $t=$ $0.46 / 0.36 / 0.35, P=0.64 / 0.72 / 0.73$; Fig 2; Table 2 ).

\section{HYBRID INVIABILITY}

We obtained 105 clutches from 15 crosses with parental species divergence times ranging from several thousand to 6.2/9/19.6 my.

Hybrid inviability increased significantly with divergence time for two of the four life-history stages (Table 2A, Fig. 2). Fertilization failure and 14-day mortality increased linearly with divergence time, whereas hatching mortality and 180-day mortality were unrelated to divergence time. Cumulative inviability accumulated at a decelerating rate and was best explained by a logarithmic function (Table 2A, Fig. 2K).

Again, the raw data and phylogenetic contrasts yielded nearly identical results despite the difference in sample sizes (Table 2B, Fig. 2). Inviability resulting from fertilization failure and 14-day mortality was negligible for species pairs separated for up to 1.2/0.9/1.5 my, reached 50\% at ca. 2.8/4.0/7.9 my, and resulted in nearly complete isolation by 4.3/8.3/17.9 my.

Juvenile survival (14-day mortality) determined hybrid inviability. All fish that successfully hatched from parents with $\geq 4.4 / 8.5 / 18.4$ my divergence time died within 14 days (crosses 22 and 21 , Table 1 ). In clutches from parents with $\geq 2.7 / 3.8 / 7.4$ my divergence time, $49 \%$ of the hatchlings survived beyond 14 days and were successfully raised to adulthood (i.e., until 180 days, cross 12). Complete fertilization failure was observed after 4.5/9.0/19.6 my divergence (crosses 22 and 23). After 


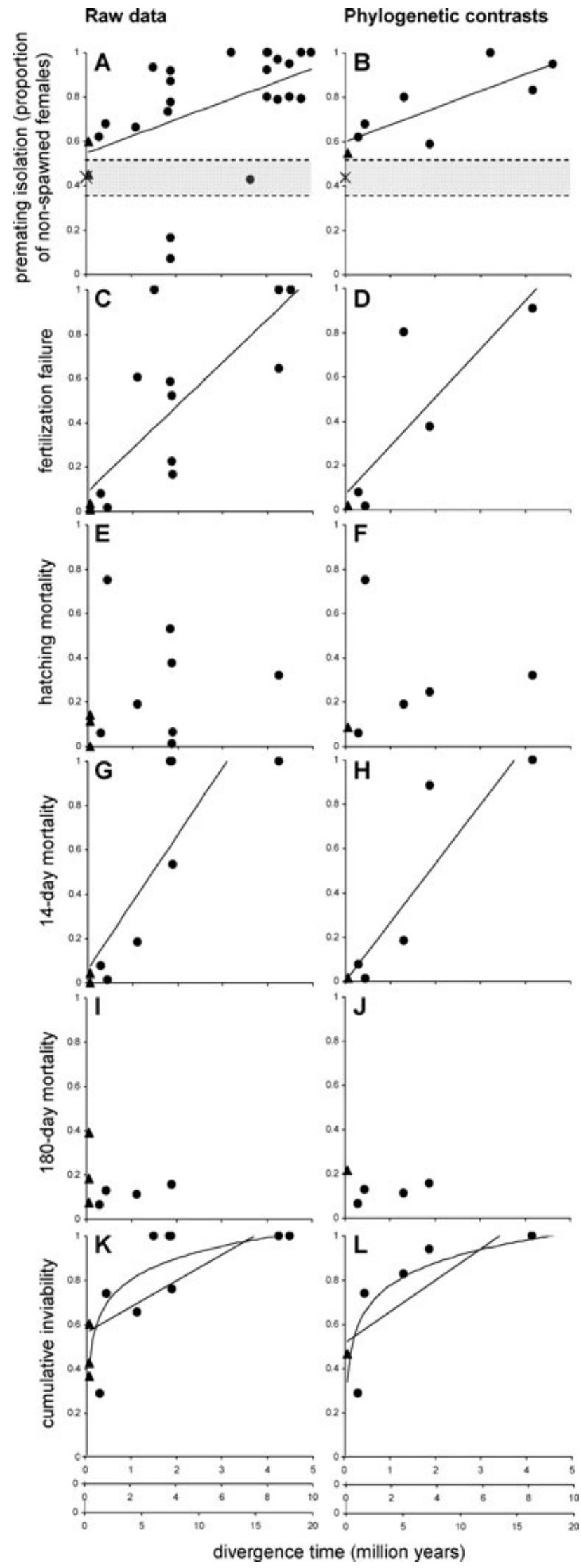

Figure 2. Accumulation of premating isolation and hybrid inviabilities as a function of divergence time based on three
4.4/8.5/18.4 my, on average $48 \%$ of eggs per clutch were successfully fertilized, of which $68 \%$ hatched (but then died within 14 days, crosses 22 and 21).

Adjusting these data for the viability found in homospecific crosses (which we called "postmating incompatibility" above) did not change the results. As above, only fertilization failure and 14-day mortality increased significantly with node age with a linear model providing the best fit whereas hatching and 180-day mortality were not affected (Table A1A, Fig. A1). Confirming the results from the unadjusted data, incompatibilities (based on 14-day survival) reached 50\% after ca 2.8/4.0/7.9 my and reached complete incompatibility first after a node age of 4.4/8.5/18.4 my. Cumulative incompatibility increased rapidly first, but then at a decelerating rate. Analysis of the phylogenetic contrasts yielded similar results (Table A1B, Fig. A1).

Interestingly, incompatibility generally started off very low, in the case of 14-day and 180-day mortality even below $0 \%$, suggesting that hybrids between the most closely related species (crosses within Lake Victoria) had higher survival rates than the corresponding homospecific crosses.

\section{COMPARING THE ACCUMULATION RATES OF PREMATING ISOLATION AND HYBRID INVIABILITY}

After subtracting the homospecific value from all interspecific datapoints of premating isolation (using contrast data), we used $t$-tests to compare the slopes and intercepts of the relationships between premating isolation and hybrid inviability on divergence time (computed as the difference between the slopes/intercepts, divided by the standard error of the difference between the slopes/intercepts). The intercept for premating isolation was

different molecular clocks. Upper $x$-axis shows divergence times calibrated to the biogeography of Lake Malawi; middle $x$-axis shows divergence times calibrated to the fossil record plus recent biogeographical events; lower $x$-axis shows divergence times calibrated to the break up of Gondwanaland plus recent biogeographical events. Premating isolation was calculated from data on the proportion of nonbreeding females. Hybrid inviability was calculated from data on fertilization, hatching, survival after 14 days, and survival after 180 days. Cumulative inviability $(K, L)$ contains all four life-history stages. Left column: Each datapoint represents a different hybrid cross. Right column: Each datapoint represents one phylogenetically independent contrast in reproductive isolation and in divergence time. Triangles indicate sympatric species crosses. Asterisks indicate the mean strength of premating isolation in homospecific crosses. The gray zones in (A) and (B) indicate the $95 \%$ confidence interval around the homospecific isolation mean. Regression lines are only shown where significant. In $(K, L)$ both logarithmic and linear regression lines are shown for a better comparison with the premating data. Results of all regression analyses can be found in Table 2 . 


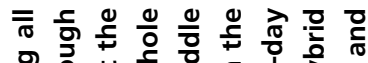

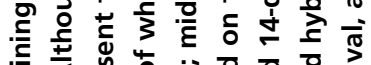

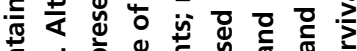

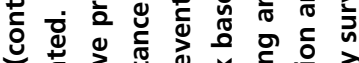

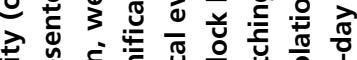

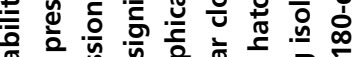

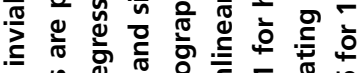

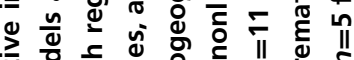

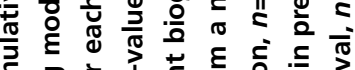

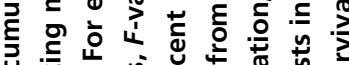

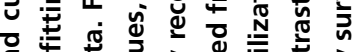

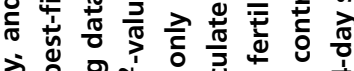

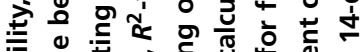

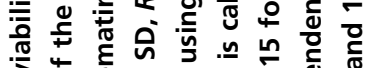

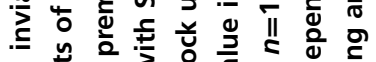
은

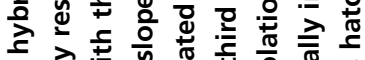

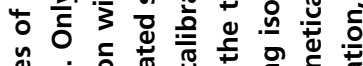

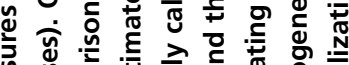
跑

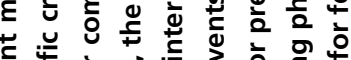

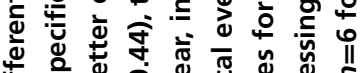

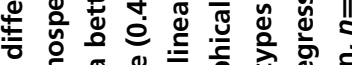

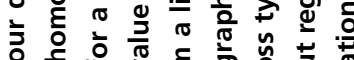

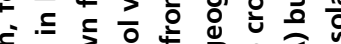

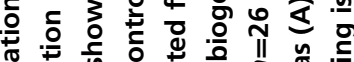
$\frac{\pi}{0} \frac{\pi}{6}$ 至

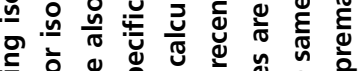

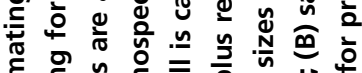

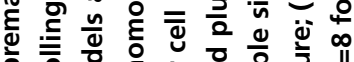

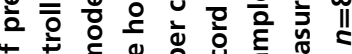
응

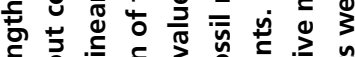

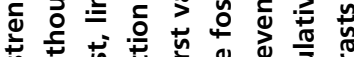

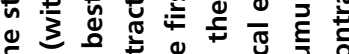
क 证 을

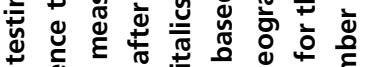

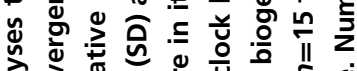
สิ

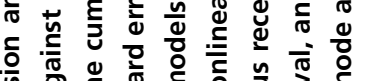
음

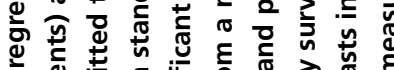

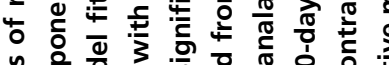

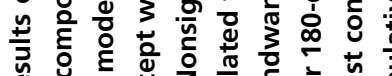

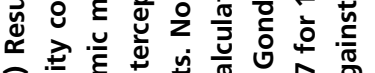
उ

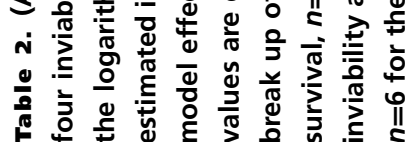

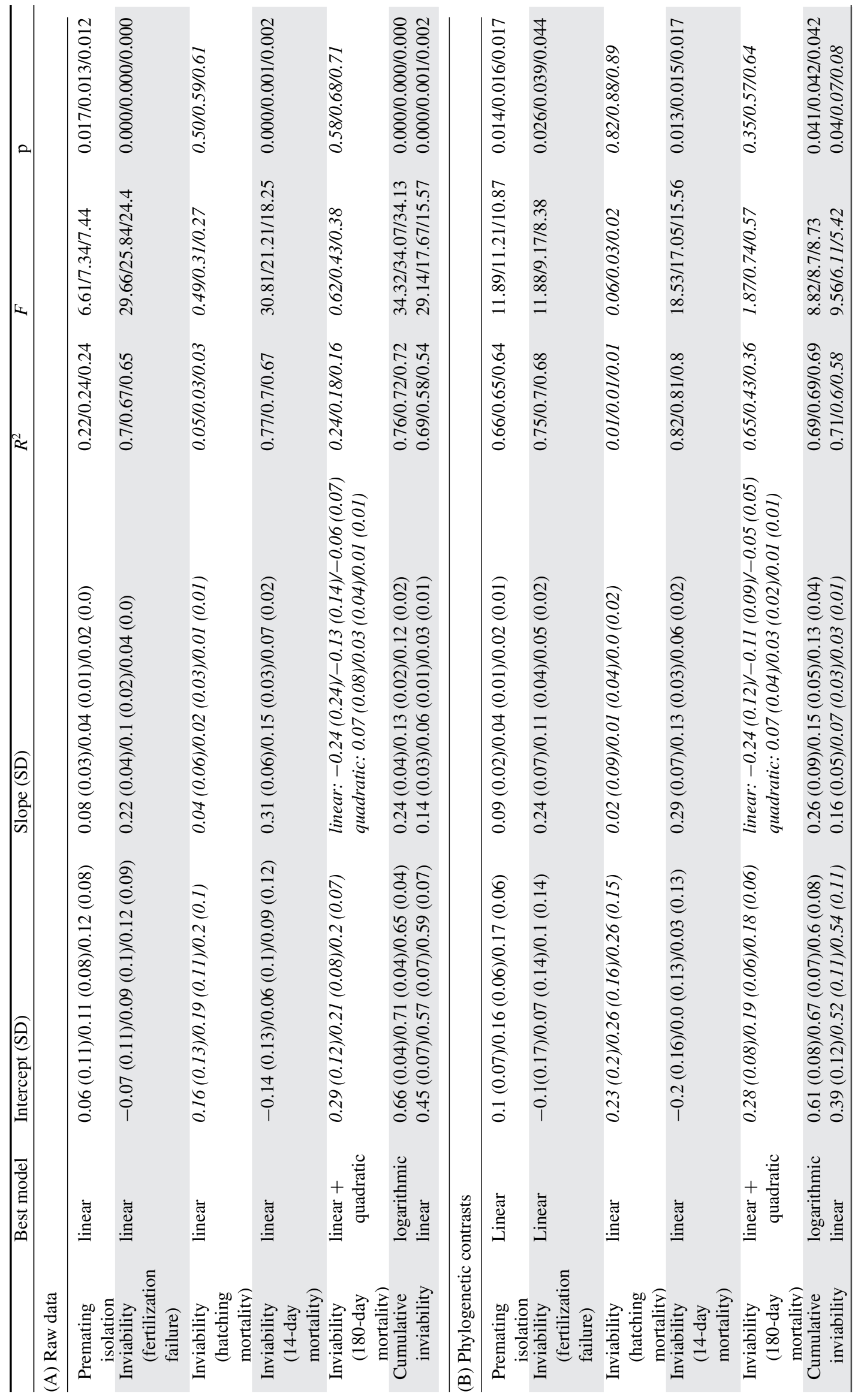


higher than that for fertilization failure, but the difference was significant only for the internally calibrated clock regressions ( $t=3.17 / 1.67 / 1.37, P=0.007 / 0.12 / 0.19$, using data on phylogenetic contrasts). The intercept was significantly higher than that for 14-day mortality with all three molecular clocks $(t=$ 4.84/3.27/2.86, all $P<0.05$ ). Hybrid inviability increased at a significantly faster rate than premating isolation for both fertilization failure $(t=5.93 / 5.35 / 5.14$, all $P<0.001)$ and 14-day mortality ( $t=8.0 / 7.9 / 7.6$, all $P<0.001)$. Fertilization failure increased by $24 / 11 / 5 \%$ per my, 14 -day mortality by $29 / 13 / 6 \%$ per million years, and premating isolation by $9 / 4 / 2 \%$ per million years.

A nonlinear, logarithmic model provided the best fit for total inviability but prevented us from comparing the accumulation rates and intercepts of premating isolation and cumulative inviability. Hence, in addition to the logarithmic regression, we also fit a linear model here to provide a meaningful comparison with the premating data (Table 2, Fig. 2). The intercepts of premating isolation and cumulative inviability did not significantly differ $(t=$ $0.06 /-0.08 /-0.10, P=0.96 / 0.93 / 0.92)$, but total hybrid inviability increased at a significantly faster rate than premating isolation ( $t$-tests on slopes: $t=3.74 / 3.03 / 2.84$, all $P=0.002 / 0.01 / 0.013$ ) with $16 / 7 / 3 \%$ per million years.

Together, these results suggest that premating isolation accumulates faster initially but then changes slowly with increasing genetic distance between species, only reaching completion after $>4.8 / 10 / 22$ my. In contrast, postmating isolation is weak between closely related species, but then increases relatively rapidly with complete hybrid inviability occurring at 4.4/8.5/18.4 million years. This suggests that successful hybridization is ultimately limited by hybrid inviability rather than by premating isolation.

\section{Discussion}

Reproductive compatibility between species typically decreases with time since geographic isolation, leading to the inference that progress toward speciation can be accurately predicted from the length of time spent in allopatry (Coyne and Orr 1998; Orr and Turelli 2001). Two principal caveats temper this assumption (Edmands 2002; Bolnick and Near 2005; Bolnick et al. 2006). First, divergence time is typically estimated by genetic distance using molecular clocks that assume mutations accumulate constantly through time and across lineages. Second, it may be misleading to draw conclusions about the relationship between reproductive compatibility and divergence time based on measurements of hybrid inviability at a single life-history stages. We have overcome both these problems by using multiple relaxed molecular clocks and quantifying premating isolation and postmating isolation from fertilization through to adulthood.

The uncertainty about the rate at which incompatibilities accumulate is highlighted by the wide range of reported estimates of the time to hybrid inviability. Divergence times of 1.5-3.5 my seem sufficient to cause strong hybrid inviability in Drosophila (Coyne and Orr 1989), anurans (Sasa et al. 1998), sea stars (Foltz 1997), sea urchins (Lessios and Cunningham 1990), and shrimps (Knowlton et al. 1993). Viable hybrids have been observed between mammalian taxa separated by 8 my (Fitzpatrick 2004). In centrarchid fish, the successful production of hybrids does not seem to cease until 29 my (Bolnick and Near 2005), although this estimate only refers to the viability of larval hybrids and survival to adulthood is likely lost faster due to juvenile mortality. Birds seem able to successfully hybridize up to $55 \mathrm{my}$, but fertility of these crosses was never confirmed (Prager and Wilson 1975; Cooper and Penny 1997; Price and Bouvier 2002). These data together with our results based on three different molecular clocks, speak strongly for the fact that much more work is required before we will establish general rules for the different components of hybrid incompatibility across taxa. Our method to estimate divergence times, and the components of hybrid inviability we chose to measure, differ from those in other studies. Thus, the high variation in the rate of incompatibility accumulation across taxa could be as likely the result of the varied ways different studies measure their variables as it could have a real underlying biological cause.

Our study reveals that, in African haplochromine cichlids, premating isolation increases rapidly early, but thereafter at a rate of $9 / 4 / 2 \%$ per million years divergence time. Two components of postmating incompatibility increase linearly with divergence time, and more than two times faster than premating isolation: fertilization failure increases at $24 / 11 / 5 \%$, and 14 -day mortality at $29 / 13 / 6 \%$ per million years. Total inviability increased at a rate of $16 / 7 / 3 \%$ per million years. Similar to previous studies (Coyne and Orr 1997; Price and Bouvier 2002; Mendelson 2003; Bolnick and Near 2005), the weighted node-averaging procedure used to improve phylogenetic dependence reduced sample sizes and power but did not qualitatively affect the results.

Theoretical work predicts that in species with strong sexual selection, premating isolation can emerge faster than postmating compatibilities in allopatry because sexual selection can drive rapid divergence in female mate choice preferences and male signals (Fisher 1930; Lande 1981; West-Eberhard 1983). In agreement with this prediction, Mendelson (2003) demonstrated that in sexually dimorphic darter fish (Etheostoma) premating isolation between allopatric species accumulated at a faster rate than postzygotic incompatibility. In the mostly allopatric cichlid species pairs we used here (Table 1), the opposite pattern may hold; despite an early jump in premating isolation, the accumulation of postmating incompatibilities proceeds two to three times faster than premating isolation. However, it is important to keep in mind that there may be other factors contributing to postmating incompatibility, such as hybrid sterility and ecologically dependent, extrinsic isolation mechanisms that we have not quantified 


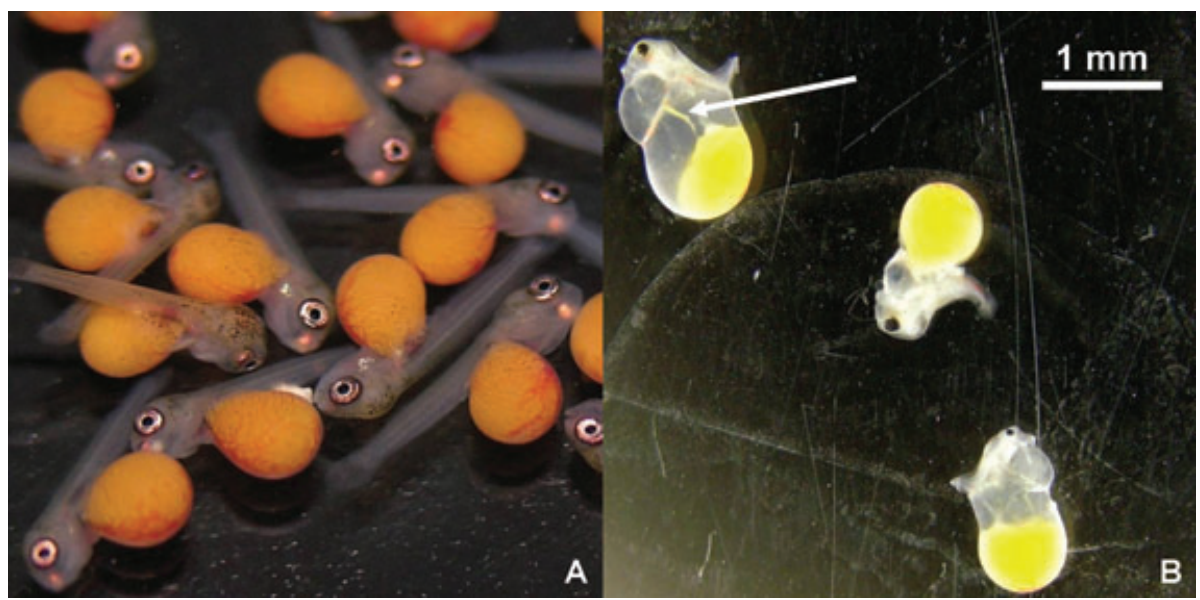

Figure 3. (A) Morphologically normal and (B) deformed nine-day-old hybrid larvae. Scale bar is approximate. Arrow indicated the deformity that appears to correspond to the "heartstring" syndrome described for zebrafish and recently observed in sunfish hybrids. See discussion for references.

here, which may also impact accumulation rates. First crossing experiments with the F1 families surviving to adulthood however indicate that all hybrid cross types are fully fertile (C. Schmid, R. B. Stelkens and O. Seehausen, unpubl. ms.).

Our results thus also contradict the prediction that pre- and postmating incompatibilities accumulate at similar rates in allopatry because divergent selection and genetic drift affect every trait type equally (Coyne and Orr 2004). The pattern we found may be explained by the fact that cichlid fish have a highly conserved courtship behavior across lineages (McElroy and Kornfield 1990). If basic male courtship behavior affects female mate choice, its invariance across lineages would reduce the rate at which premating isolation emerges. Comparative mate choice studies using closely related species or populations of cichlids have shown that genetic unrelatedness is often not linked to the strength of assortative mating (Seehausen et al. 1998; Knight and Turner 2004; Plenderleith et al. 2005; Stelkens and Seehausen 2009) supporting the notion that only after lineages have diverged significantly, does genetic distance predict the degree of premating isolation in cichlid fish. It should, however, be noted that because we measured premating isolation in no-choice experiments and under laboratory conditions, our estimate of the speed of incompatibility accumulation due to premating barriers may not be precise. In the wild (and in the presence of conspecific males), females may discriminate more strongly against heterospecific males, and hence we may have underestimated the strength of sexual isolation between species.

Our finding that intrinsic postmating incompatibility is stage-specific demonstrates that studies using single measures of hybrid inviability may lead to inaccurate conclusions about the relationship between hybrid fitness and genetic distance. The principal mechanisms responsible for hybrid viability operate during zygote formation and posthatching larval development.
Had we measured hybrid inviability using only fertilization failure, however, we would have underestimated the rate at which hybrid incompatibility accumulates. This again highlights the fact that one should be cautious with cross-taxonomic conclusions about which isolation mechanism is operational in a specific group of species. For instance, in centrarchid fish, fertilization isolation was found to be mostly absent (West and Hester 1966; Merriner 1971) whereas fertilization failure was an important contributor to isolation in our study.

We identified one possible isolation mechanism during the posthatching larval stage; a developmental deformity that occurred in numerous hybrid clutches (Fig. 3). It resembles the heartstrings developmental mutation observed first in zebrafish (Garrity et al. 2002) and more recently in centrarchid hybrids (López-Fernández and Bolnick 2008). The heart develops normally during early embryonic stages, but suffers "looping failure" and adopts a string-like and elongate shape during the hatchling stage. In zebrafish, the deformation is caused by a homozygous recessive mutation that can also lead to heart diseases in mice and humans (Garrity et al. 2002) and López-Fernández and Bolnick (2008) suggested this may be the first candidate in vertebrates for a locus affected by Dobzhansky-Muller epistatic effects. Identifying the genetic basis of this syndrome in cichlids and centrarchids remains an important and outstanding challenge.

Dobzhanzky-Muller incompatibilities are assumed to form the basis of most intrinsic hybrid inviabilities (Orr and Turelli 2001). They typically evolve as pleiotropic byproducts of genetic drift or natural selection after populations become isolated and are neutral or beneficial in their population of origin, but show negative epistasis when combined in a hybrid genome (Turelli and Orr 2000). Epistatic effects accumulate in a quadratic fashion in the Dobzhanzky-Muller model (Orr 1995), which is why incompatibility is predicted to increase slowly with genetic distance at 
first but then with accelerating speed (but note that this prediction does not always hold, e.g., in spatially structured populations [Kondrashov 2003]). There is some evidence for an accelerating increase in reproductive isolation with time in darter fish (Mendelson 2003). Also, some curvature of the regression line is documented in centrachid fish although this may be the result of a lag-time arising from heterosis among closely related taxa rather than being the effect of an increase in the number of incompatibilities with the square of time (Bolnick and Near 2005). Apart from these studies, there is little evidence for this expected "snowball effect" (Orr 1995; Johnson 2006). In fact, we add our results to a growing body of work revealing a linear rather than accelerating decrease in compatibility over time (Coyne and Orr 1989, 1997; Turelli and Begun 1997; Sasa et al. 1998; Presgraves 2002; Price and Bouvier 2002). The decelerating accumulation of postmating reproductive isolation may suggests a "diminishing returns" relationship between the number of incompatibilities and the extent of reproductive isolation, such that the marginal contribution of a factor decreases with the number of factors involved in isolation. A related explanation for the apparent lack of the snowball effect in empirical data is that the number of genes causing postzygotic isolation and the resulting strength or intensity of that isolation may not be directly related. If this was the case, the strength of isolation may take any function of genetic distance, not necessarily quadratic. For instance, Sasa et al. (1998) have suggested an asymptotic relationship between the number of incompatibility factors and indices of reproductive isolation. Alternatively, S. Gourbière and J. Mallet (unpubl. ms.) suggest that, along with statistical noise and nonlinearity in the speciation clock, few genes with major and variable effects and the concurrence of several different overlapping "snowball" processes may obscure the expected snowball pattern.

To our knowledge, this is the first study of reproductive incompatibilities to convert genetic distances into absolute divergence times using relaxed molecular clocks. Identifying the divergence time limit for hybrid viability is important because molecular genetic evidence suggests hybridization may be involved in the early stages of adaptive radiation (Seehausen et al. 2003; Seehausen 2004). These observations motivated the "hybrid swarm origin" hypothesis (Seehausen 2004), which posits that hybridization is common when species invade new environments and generates increased levels of heritable phenotypic variation upon which diversifying ecological selection can act. Early hybridization thus facilitates rapid adaptive divergence whereas ongoing hybridization helps maintain genetic variation that would otherwise be eroded by directional selection. Our results confirm and set an upper time limit on the feasibility of the hybrid swarm origin hypothesis by showing that viable hybrids are produced by distantly related species (4.4/8.5/18.4 my). This time frame is consistent with the estimated divergence times of the putative ancestors of the cichlid radiations of Lake Victoria (Seehausen et al. 2003) and paleo-Lake Makgadikgadi (Joyce et al. 2005). Intriguingly, our incompatibility data reveal that hybrids have higher survival rates than their parental taxa after the larval stage. Such heterosis-like effects on hybrid viability due to the overall increased heterozygosity in the F1 generation could further enhance the role of hybridization in driving adaptive radiation. However, hybrid breakdown in later generations would counteract any such effect (Wu and Palopoli 1994; Wiley et al. 2009). Wiley et al. (2009) examined if the reproductive output of F1 hybrids is a good proxy for long-term fitness consequences of hybridization between two bird species, and found that F1 hybrid fitness greatly underestimated the extent of postzygotic isolation after multiple generations. We are currently extending our experiment to F2 generation hybrids to explore this topic (C. Schmid, R. B. Stelkens and O. Seehausen, unpubl. ms.).

One challenge raised by the hybrid swarm hypothesis is whether the sequence haplotypes used to date divergence time between species are actually an appropriate tool to measure "time since speciation." Extensive hybridization may cause that distant lineages possess more similar haplotypes than close relatives (Joyce et al. 2005). Thus, hybridization might complicate speciation clock studies. The accuracy of the estimated time to isolation not only depends on the molecular marker, the assumptions of the molecular clock, and the viability measure used, but also on how long ago and how much hybridization has taken place. Our dataset should be relatively robust toward the latter because most of our crosses were produced between members of different radiations.

We conclude by noting that our results suggest the waiting time to complete intrinsic isolation between haplochromine cichlid species is orders of magnitude higher than the rates of speciation observed within individual lake radiations (Seehausen 2006). This finding contradicts threshold-based incompatibility models assuming the time to complete hybrid inviability equals the time since speciation (Orr and Turelli 2001; Turelli and Moyle 2007) and is consistent with the idea that speciation in cichlid radiations is driven principally by divergent ecological and sexual selection rather than by the accumulation of intrinsic hybrid incompatibilities (Kornfield and Smith 2000; Seehausen 2000; Streelman and Danley 2003; Kocher 2004; Stelkens and Seehausen 2009). If such selective forces are principally responsible for driving and maintaining species diversity, environmental changes that reduce the strength of diversifying natural and sexual selection may threaten taxonomic and functional diversity of the Great Lake cichlid radiations (Seehausen et al. 1997).

\section{ACKNOWLEDGMENTS}

We thank J.P. Danko for commenting on the manuscript, for help with the comparative method, and for many stimulating discussions. Thanks also to E. Schaeffer and A. Taverna who helped raising the fish. Finally, 
we thank D. Bolnick and two anonymous referees for their excellent comments on an earlier draft of this article. During the preparation of the manuscript, KAY received support from a Darwin Initiative grant no. 162-15-020 (DEFRA, U.K.). This research was supported by the Swiss Science Foundation (Schweizer Nationalfond) to OS.

\section{LITERATURE CITED}

Bolnick, D. I., and T. J. Near. 2005. Tempo of hybrid inviability in centrarchid fishes (Teleostei: Centrarchidae). Evolution 59:1754-1767.

Bolnick, D. I., T. J. Near, and P. C. Wainwright. 2006. Body size divergence promotes post-zygotic reproductive isolation in centrarchids. Evol. Ecol. Res. 8:903-913.

Bridle, J. R., C. I. Saldamando, W. Koning, and R. K. Butlin. 2006. Assortative preferences and discrimination by females against hybrid male song in the grasshoppers chorthippus brunneus and chorthippus jacobsi (Orthoptera : Acrididae). J. Evol. Biol. 19:1248-1256.

Butlin, R. K. 1989. Reinforcement of premating isolation. Pp. 158-179 in D. Otte and J. A. Endler, eds. Speciation and its consequences. Sinauer Associates Inc., Sunderland, MA.

Chapman, M. A., and J. M. Burke. 2007. Genetic divergence and hybrid speciation. Evolution 61:1773-1780.

Cooper, A., and D. Penny. 1997. Mass survival of birds across the cretaceoustertiary boundary: molecular evidence. Science 275:1109-1113.

Coyne, J. A., and H. A. Orr. 1989. Patterns of speciation in drosophila. Evolution 43:362-381.

1997. "Patterns of speciation in drosophila" revisited. Evolution 51:295-303.

- 1998. The evolutionary genetics of speciation. Philos. Trans. R. Soc. Lond. B 353:287-305.

- 2004. Speciation. Sinauer Associates, Sunderland, MA.

Dobzhansky, T. 1936. Studies on hybrid sterility. ii. localization of sterility factors in drosophila pseudoobscura hybrids. Genetics 21:113-135.

. 1951. Genetics and the origin of species. Columbia Univ. Press, New York.

Edmands, S. 1999. Heterosis and outbreeding depression in interpopulation crosses spanning a wide range of divergence. Evolution 53:1757-1768.

. 2002. Does parental divergence predict reproductive compatibility? Trends Ecol. Evol. 17:520-527.

Felsenstein, J. 1985. Phylogenies and the comparative method. Am. Nat. 125:1-15.

Fisher, R. A. 1930. The genetical theory of natural selection. Clarendon Press, Oxford.

Fitzpatrick, B. M. 2004. Rates of evolution of hybrid inviability in birds and mammals. Evolution 58:1865-1870.

Foltz, D. W. 1997. Hybridization frequency is negatively correlated with divergence time of mitochondrial DNA haplotypes in a sea Star (Leptasterias spp) species complex. Evolution 51:283-288.

Fuller, R. C. 2008. Genetic incompatibilities in killifish and the role of environment. Evolution 62:3056-3068.

Garrity, D., S. Childs, and M. Fishman. 2002. The heartstrings mutation in zebrafish causes heart/fin Tbx 5 deficiency syndrome. Development 129:4635-4645.

Genner, M. J., O. Seehausen, D. H. Lunt, D. A. Joyce, P. W. Shaw, R. Carvalho, and G. T. Turner. 2007. Age of cichlids: new dates for ancient lake fish radiations. Mol. Biol. Evol. 24:1269-1282.

Gharrett, A. J., W. W. Smoker, R. R. Reisenbichler, and S. G. Taylor. 1999. Outbreeding depression in hybrids between odd- and even-broodyear salmon. Aquaculture 173:117-129.

Gleason, J. M., and M. G. Ritchie. 1998. Evolution of courtship song and reproductive isolation in the drosophila willistoni species complex: do sexual signals diverge the most quickly? Evolution 52:1493-1500.
Hatfield, T., and D. Schluter. 1999. Ecological speciation in sticklebacks: environment-dependent hybrid fitness. Evolution 53:866-873.

Ho, S. Y. W. 2007. Calibrating molecular estimates of substitution rates and divergence times in birds. J. Avian Biol. 38:409-414.

Ho, S. Y. W., and G. Larson. 2006. Molecular clocks: when times are achangin'. Trends Genet. 22:79-83.

Howard, D. J., and S. H. Berlocher. 1998. Endless forms: species and speciation. Oxford University Press, New York.

Jiggins, C. D., R. E. Naisbit, R. L. Coe, and J. Mallet. 2001. Reproductive isolation caused by colour pattern mimicry. Nature 411:302-305.

Johnson, N. A. 2006. Patterns and processes of speciation: the evolution of reproductive isolating barriers. Pp. 374-386 in C. W. Fox and J. B. Wolf, eds. Evolutionary genetics. concepts and case studies. Oxford Univ. Press, Oxford.

Joyce, D. A., D. H. Lunt, R. Bills, G. F. Turner, C. Katongo, N. Duftner, C. Sturmbauer, and O. Seehausen. 2005. An extant cichlid fish radiation emerged in an extinct pleistocene lake. Nature 435:90-95.

Knight, M. E., and G. F. Turner. 2004. Laboratory mating trials indicate incipient speciation by sexual selection among populations of the cichlid fish pseudotropheus zebra from lake Malawi. Proc. R. Soc. Lond. B 271:675-680.

Knowlton, N., L. A. Weigt, L. A. Solorzano, D. K. Mills, and E. Bermingham. 1993. Divergence in proteins, mitochondrial-DNA, and reproductive compatibility across the Isthmus of Panama. Science 260:1629-1632.

Kocher, T. D. 2004. Adaptive evolution and explosive speciation: the cichlid fish model. Nat. Rev. Genet. 5:288-298.

Kondrashov, A. S. 2003. Accumulation of Dobzhansky-Muller incompatibilities within a spatially structured population. Evolution 57:151-153.

Kornfield, I., and P. F. Smith. 2000. African cichlid fishes: model systems for evolutionary biology. Annu. Rev. Ecol. Syst. 31:163-196.

Kumar, S., K. Tamura, and M. Nei. 2004. Mega3: integrated software for molecular evolutionary genetics analysis and sequence alignment. Brief. Bioinform. 5:150-163.

Lande, R. 1981. Models of speciation by sexual selection on polygenic traits. Proc. Natl. Acad. Sci. USA 78:3721-3725.

Lessios, H. A., and C. W. Cunningham. 1990. Gametic incompatibility between species of the sea-urchin echinometra on the 2 sides of the Isthmus of Panama. Evolution 44:933-941.

Lijtmaer, D. A., B. Mahler, and P. L. Tubaro. 2003. Hybridization and postzygotic isolation patterns in pigeons and doves. Evolution 57:1411-1418.

López-Fernández, H., and D. I. Bolnick. 2008. What causes partial F1 hybrid viability? Incomplete penetrance versus genetic variation. Plos ONE 2:e1294.

Lowry, D. B., J. L. Modliszewski, K. M. Wright, C. A. Wu, and J. H. Willis. 2008. The strength and genetic basis of reproductive isolating barriers in flowering plants. Philos. Trans. R. Soc. Lond. B 363:3009-3021.

Lynch, M. 1991. The genetic interpretation of inbreeding depression and outbreeding depression. Evolution 45:622-629.

Maan, M. E., O. Seehausen, L. Soderberg, L. Johnson, E. A. P. Ripmeester, H. D. J. Mrosso, M. I. Taylor, T. J. M. van Dooren, and J. J. M. van Alphen. 2004. Intraspecific sexual selection on a speciation trait, male coloration, in the lake victoria cichlid Pundamilia nyererei. Proc. R. Soc. Lond. B 271:2445-2452.

Malone, J., and B. Fontenot. 2008. Patterns of reproductive isolation in toads. Plos ONE 3:e3900.

McElroy, D. M., and I. Kornfield. 1990. Sexual selection, reproductivebehavior, and speciation in the mbuna species flock of Lake Malawi (Pisces, Cichlidae). Environ. Biol. Fishes 28:273-284.

Mendelson, T. C. 2003. Sexual isolation evolves faster than hybrid inviability in a diverse and sexually dimorphic genus of fish (Percidae: Etheostoma). Evolution 57:317-327. 
Merriner, J. V. 1971. Development of intergeneric centrarchid hybrid embryos. Trans. Am. Fisheries Soc. 100:611-618.

Moyle, L. C., M. S. Olson, and P. Tiffin. 2004. Patterns of reproductive isolation in three angiosperm genera. Evolution 58:1195-1208.

Muller, H. J. 1942. Isolating mechanisms, evolution and temperature. Pp. 71-125. Biological Symposium 6:71-125.

Naisbit, R. E., C. D. Jiggins, and J. Mallet. 2001. Disruptive sexual selection against hybrids contributes to speciation between Heliconius cydno and Heliconius melpomene. Proc. R. Soc. Lond. B 268:1849-1854.

Nei, M. 1987. Molecular evolutionary genetics. Columbia Univ. Press, New York.

Noor, M. A. F. 1997. Genetics of sexual isolation and courtship dysfunction in male hybrids of Drosophila pseudoobscura and Drosophila persimilis. Evolution 51:809-815.

Nosil, P., B. J. Crespi, and C. P. Sandoval. 2003. Reproductive isolation driven by the combined effects of ecological adaptation and reinforcement. Proc. R. Soc. Lond. B 270:1911-1918.

Orr, H. A. 1995. The population genetics of speciation-the evolution of hybrid incompatibilities. Genetics 139:1805-1813.

Orr, H. A., and M. Turelli. 2001. The evolution of postzygotic isolation: accumulating Dobzhansky-Muller incompatibilities. Evolution 55:10851094.

Otte, D., and J. A. Endler. 1989. Speciation and its consequences. Sinauer Associates, Sunderland, MA.

Parker, H. R., D. P. Philipp, and G. S. Whitt. 1985a. Gene regulatory divergence among species estimated by altered developmental patterns in interspecific hybrids. Mol. Biol. Evol. 2:217-250.

. 1985b. Relative developmental success of interspecific Lepomis hybrids as an estimate of gene regulatory divergence between species. J. Exp. Zool. 233:451-466.

Pauers, M. J., J. S. McKinnon, and T. J. Ehlinger. 2004. Directional sexual selection on chroma and within-pattern colour contrast in Labeotropheus fuelleborni. Proc. R. Soc. Lond. B 271:S444-S447.

Plenderleith, M., C. van Oosterhout, R. L. Robinson, and G. F. Turner. 2005. Female preference for conspecific males based on olfactory cues in a Lake Malawi cichlid fish. Biol. Letts. 1:411-414.

Prager, E. M., and A. C. Wilson. 1975. Slow evolutionary loss of potential for interspecific hybridization in birds-manifestation of slow regulatory evolution. Proc. Natl. Acad. Sci. USA 72:200-204.

Presgraves, D. C. 2002. Patterns of postzygotic isolation in Lepidoptera. Evolution 56:1168-1183.

Price, T. D., and M. M. Bouvier. 2002. The evolution of F-1 postzygotic incompatibilities in birds. Evolution 56:2083-2089.

Rundle, H. D., and D. Schluter. 1998. Reinforcement of stickleback mate preferences: sympatry breeds contempt. Evolution 52:200-208.

Sasa, M. M., P. T. Chippindale, and N. A. Johnson. 1998. Patterns of postzygotic isolation in frogs. Evolution 52:1811-1820.

Scopece, G., A. Musacchio, A. Widmer, and S. Cozzolino. 2007. Patterns of reproductive isolation in Mediterranean deceptive orchids. Evolution 61:2623-2642.

Seehausen, O. 1997. Distribution of and reproductive isolation among color morphs of a rock-dwelling Lake Victoria cichlid (Haplochromis nyererei). Ecol. Freshwat. Fish 5:59-66.

- 2000. Explosive speciation rates and unusual species richness in haplochromine cichlid fishes: effects of sexual selection. Adv. Ecol. Res. 31:237-274.

. 2004. Hybridization and adaptive radiation. Trends Ecol. Evol. 19:198-207.

2006. African cichlid fish: a model system in adaptive radiation research. Proc. R. Soc. Lond. B 273:1987-1998.

Seehausen, O., J. J. M. Van Alphen, and F. Witte. 1997. Cichlid fish diver- sity threatened by eutrophication that curbs sexual selection. Science 277:1808-1811.

Seehausen, O., F. Witte, J. J. M. Van Alphen, and N. Bouton. 1998. Direct mate choice maintains diversity among sympatric cichlids in Lake Victoria. J. Fish Biol. 53:37-55.

Seehausen, O., E. Koetsier, M. V. Schneider, L. J. Chapman, C. A. Chapman, M. E. Knight, G. F. Turner, J. J. M. van Alphen, and R. Bills. 2003. Nuclear markers reveal unexpected genetic variation and a congolesenilotic origin of the Lake Victoria Cichlid Species Flock. Proc. R. Soc. Lond. B 270:129-137.

Servedio, M. R. 2004. The what and why of research on reinforcement. Plos Biol. 2:2032-2035.

Stelkens, R. B., and O. Seehausen. 2009. Divergent adaptation but not genetic distance predicts assortative mating among species of a new cichlid fish radiation. J. Evol. Biol. 22:1679-1694.

Stelkens, R. B., M. E. R. Pierotti, D. A. Joyce, A. M. Smith, I. Van Der Sluijs, and O. Seehausen. 2008. Disruptive sexual selection on male nuptial coloration in an experimental hybrid population of cichlid fish. Philos. Trans. R. Soc. Lond. B 363:2861-2870.

Streelman, J. T., and P. D. Danley. 2003. The stages of vertebrate evolutionary radiation. Trends Ecol. Evol. 18:126-131.

Sturmbauer, C., S. Baric, W. Salzburger, L. Rüber, and E. Verheyen. 2001. Lake level fluctuations synchronize genetic divergences of cichlid fishes in African Lakes. Mol. Biol. Evol. 18:144-154.

Thompson, J. D., T. J. Gibson, F. Plewniak, F. Jeanmougin, and D. G. Higgins. 1997. The Clustalx windows interface: flexible strategies for multiple sequence alignment aided by quality analysis tools. Nucleic Acid Res. 24:4876-4882.

Tubaro, P. L., and D. A. Lijtmaer. 2002. Hybridization patterns and the evolution of reproductive isolation in ducks. Biol. J. Linn. Soc. 77:193-200.

Turelli, M., and D. J. Begun. 1997. Haldane's rule and X—chromosome size in drosophila. Genetics 147:1799-1815.

Turelli, M., and H. A. Orr. 2000. Dominance, epistasis and the genetics of postzygotic isolation. Genetics 154:1663-1679.

Turelli, M., and L. C. Moyle. 2007. Asymmetric postmating isolation: Darwin's corollary to Haldane's Rule. Genetics 176: 1059-1088.

Turelli, M., N. H. Barton, and J. A. Coyne. 2001. Theory and speciation. Trends Ecol. Evol. 16:330-343.

Vamosi, S. M., and D. Schluter. 1999. Sexual selection against hybrids between sympatric stickleback species: evidence from a filed experiment. Evolution 53:874-879.

Van Der Sluijs, I., T. J. M. Van Dooren, K. D. Hofker, J. J. M. van Alphen, R. B. Stelkens, and O. Seehausen. 2008a. Female mating preference functions predict sexual selection against hybrids between sibling species of cichlid fish. Philos. Trans. R. Soc. Lond. B 363:2871-2877.

Van Der Sluijs, I., T. J. M. Van Dooren, O. Seehausen, and J. J. M. Van Alphen. 2008b. A test of fitness consequences of hybridization in sibling species of lake victoria cichlid fish. J. Evol. Biol. 21:480-491.

West, J. L., and F. E. Hester. 1966. Intergeneric hybridization of centrarchids. Trans. Am. Fisheries Soc. 95:280-288.

West-Eberhard, M. J. 1983. Sexual selection, social competition, and speciation. Q. Rev. Biol. 58:155-183.

Wiley, C., A. Qvarnstrom, G. Andersson, T. Borge, and G.-P. Saetre. 2009. Postzygotic isolation over multiple generations of hybrid descendants is a natural hybrid zone: how well do single-generation estimates reflect reproductive isolation? Evolution 63:1731-1739.

Wu, C. I., and M. F. Palopoli. 1994. Genetics of postmating reproductive isolation in animals. Annu. Rev. Genet. 28:283-308. 
Appendix

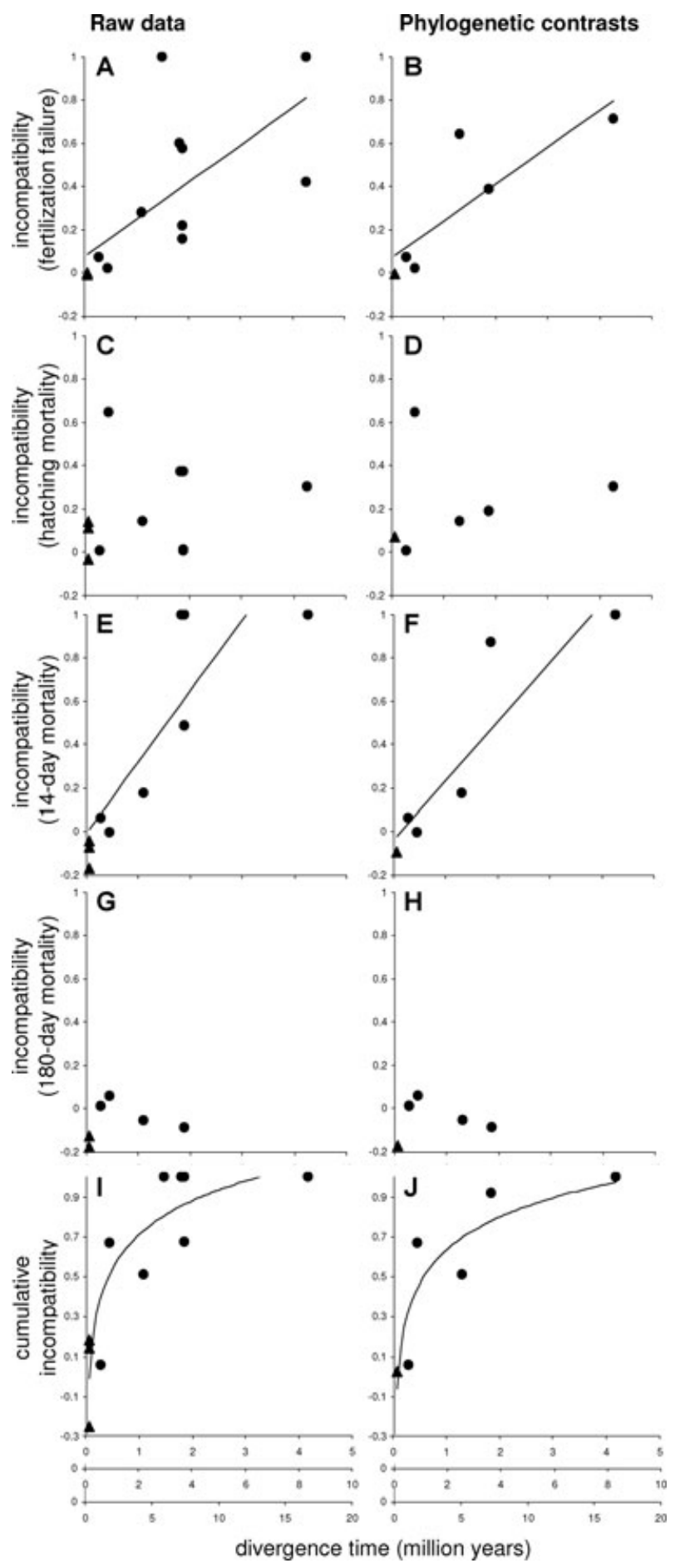

Figure A1. Accumulation of incompatibility of hetero- and homospecific crosses as a function of divergence time based on three different molecular clocks. Upper $x$-axis shows divergence times calibrated to the biogeography of Lake Malawi; middle $x$-axis shows divergence times calibrated to the fossil record plus recent biogeographical events; lower $x$-axis shows divergence times calibrated to the break up of Gondwanaland plus recent biogeographical events. Incompatibilities were calculated from hybrid inviability data (main document, Fig. 2), controlled for the inviability found in homospecific crosses. Left column: Each datapoint represents a different hybrid cross. Right column: Each datapoint represents one phylogenetically independent contrast in incompatibility and in divergence time. Incompatibilities below $0 \%$ indicate that hybrids have higher viability than the two corresponding homospecific crosses. Open circles indicate sympatric species crosses. Regression lines are only shown where significant. Results of all regression analyses can be found in Table A1. 


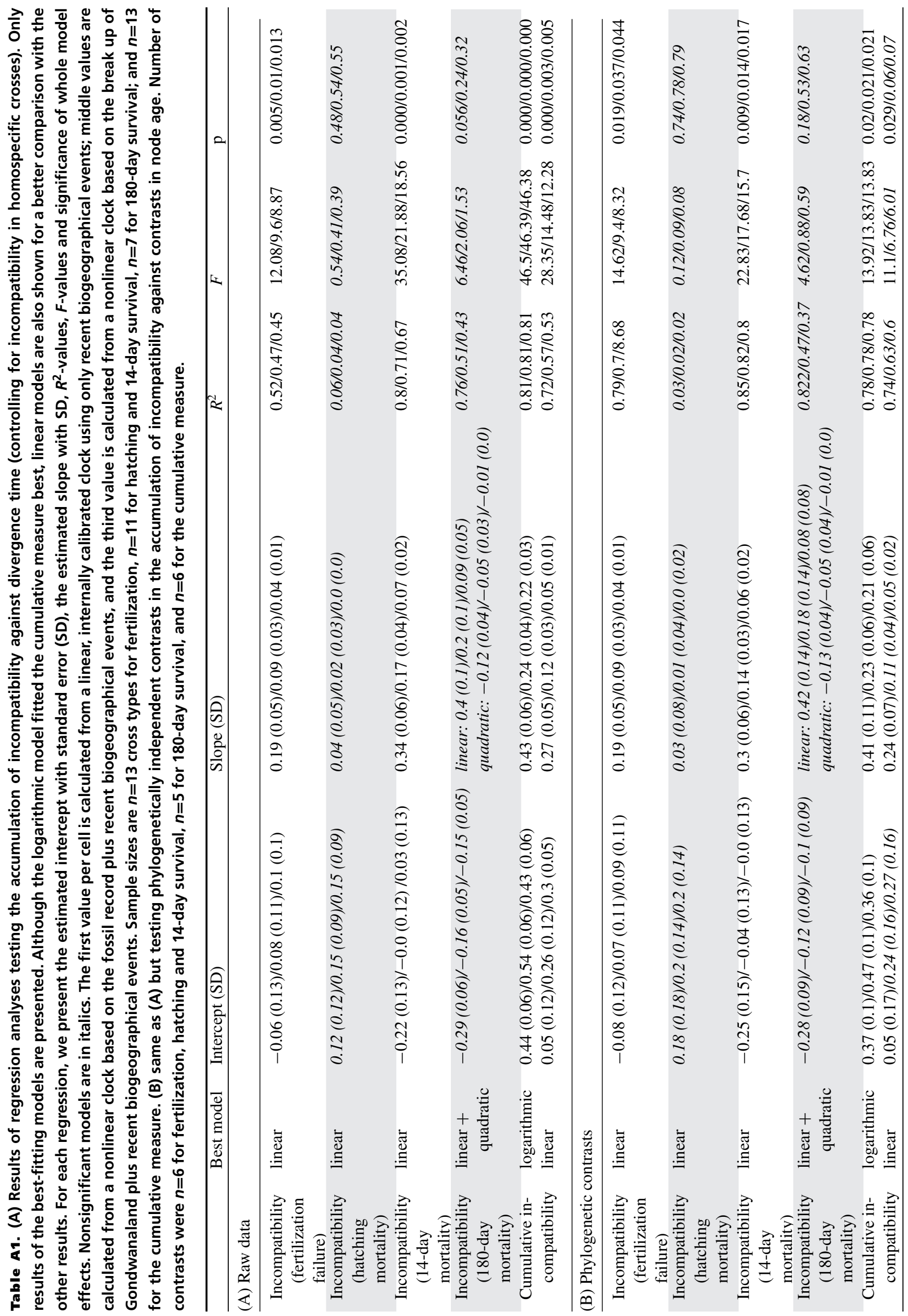




\section{Supporting Information}

The following supporting information is available for this article:

Table S1. NCBI GenBank accession numbers of D-loop sequences used for calculations of genetic distances.

Table S2. Proportion of spawned females per experimental observation unit (one aquarium per row) with cross type, genetic distance, the number of females present at the time of spawning, and the duration of the trial in number of days.

Supporting Information may be found in the online version of this article.

(This link will take you to the article abstract).

Please note: Wiley-Blackwell is not responsible for the content or functionality of any supporting informations supplied by the authors. Any queries (other than missing material) should be directed to the corresponding author for the article. 